\title{
Effect of Pass Strain on the Microstructure, Texture and Mechanical Properties of AZ31 Magnesium Alloy Fabricated by High Strain Rate Multiple Forging
}

\author{
Yuanzhi Wu ${ }^{1}$, Bin Deng ${ }^{1, *}$, Tuo Ye ${ }^{1, *}$, Wei Liu ${ }^{1}$, Zhicheng Nie ${ }^{2}$ and Xin Zhang ${ }^{2}$ \\ 1 Research Institute of Automobile Parts Technology, Hunan Institute of Technology, Hengyang 421002, China; \\ 2013001767@hnit.edu.cn (Y.W.); 2015002039@hnit.edu.cn (W.L.) \\ 2 College of Materials Science and Engineering, Hunan University of Science and Technology, \\ Xiangtan 411201, China; 15973829996@139.com (Z.N.); xzhang@hnust.edu.cn (X.Z.) \\ * Correspondence: 2005001476@hnit.edu.cn (B.D.); 2017001002@hnit.edu.cn (T.Y.); \\ Tel.: +86-15886401867 (B.D.); +86-15096039110 (T.Y.)
}

Received: 21 June 2020; Accepted: 22 July 2020; Published: 24 July 2020

\begin{abstract}
High strain rate multiple forging (HSRMF) with pass strain ranging from 0.1 to 0.35 was carried out on the AZ31 magnesium alloy, and the microstructure, texture and mechanical properties were examined. The initial grain can be refined through the formation of high density $\{102\}$ and $\{101(-) 1\}-\{101(-) 2\}$ twins and subsequently twining induced dynamic recrystallization (DRX). The grain refinement of the HSRMFed alloy was affected by the lamellar thickness of the twin. Lower pass strain $(\Delta \varepsilon=0.1)$ during HSRMF leads to the thick twin lamellae and consequently results in coarse DRX grain, meanwhile, an incomplete DRX occurs. While the twin lamellae thickness decreases with increasing pass strain, and a saturate thickness can be achieved with higher pass strain $(\Delta \varepsilon=0.16-0.35)$, which results in the finer DRX structure. Homogeneous DXR structure can be obtained only at a proper accumulated strain $\left(\sum \Delta \varepsilon=0.96-1.4\right)$ during HSRMF, under lower accumulated strain, the DRX is insufficient, while higher accumulated strain leads to abnormal grain growth. A double peak basal texture was achieved at lower pass strain $(\Delta \varepsilon=0.1)$, which developed into titled basal texture, and the texture intensity increases with the pass strain. HSRMFed alloys with homogeneous fine DRX grain and relatively weak texture show high strength and excellent ductility, therefore, and it is inferred that the optimum pass strain and accumulated strain range are $0.16-0.35$ and $0.96-1.4$ respectively.
\end{abstract}

Keywords: AZ31 alloy; high strain rate multiple forging; pass strain; mechanical property; twinning; texture

\section{Introduction}

Magnesium alloy is a kind of energy-saving and emission reduction materials, and it is widely used in the field of aeroplanes and automobile, because of its advantages of being light weight, having good machinability, excellent damping capacity and favorable recycling capability [1,2]. However, the limited strength and ductility cannot meet the requirement for its widespread application [3,4]. Many efforts have been done to develop stronger and more ductile magnesium alloy, and the development of the cost-effective processing technique has received many particular interests. It is reported that a good combination of high strength and excellent ductility can be achieved by severe plastic deformation (SPD) [5] such as accumulative roll bonding (ARB), high-pressure torsion (HPT), equal channel angular pressing (ECAP), cyclic extrusion compression (CEC), severe rolling (SR) and multiple forging (MF). $\mathrm{MF}$ is one of the most versatile techniques to produce large bulk materials with low cost, and it has been used to refine the microstructures of magnesium alloys at low strain rates forging [6-10]. Compared with multiple forging at low strain rates, high strain rate multiple forging (HSRMF) is 
more desirable for the fabrication of wrought products because of its high yield efficiency, and many studies about HSRMF of magnesium alloys have been reported in recent years. For example, Chen et al. has successfully produced AZ61 [11-13] and Mg-Gd-Y-Zr [14] alloy by adopting small strain impact multidirectional forging, meanwhile, the related microstructure, texture and mechanical properties of the forged alloys have been investigated. In our previous research, high strain rate multiple forging were successfully carried out on ZK60 [15], ZK21 [16] and AZ31 [17] magnesium alloys by using an industrial air pneumatic hammer machine, and excellent balance of strength and ductility were achieved in those alloys owing to grain refinement. As we know, the microstructure and performances of forging products are determined by the processing parameters such as the deformation route, deformation temperature, strain rate and strain [18]. Among those processing parameters, strain was reported to have great effects on the texture component [18], structure heterogeneity [19] and activation of secondary dynamic recrystallization (DRX) [20] of forging products. However, there is limited research about multiple forged magnesium alloys that focuses on the pass strain, and the influence pass strain on microstructure and performances of magnesium alloys fabricated by MF are still unknown. In this work, the effect of pass strain on the microstructure and texture of the HSRMFed AZ31 magnesium alloy and its resultant mechanical properties were systematically investigated.

\section{Experimental Procedures}

A commercial AZ31 magnesium alloy material was selected in the present study. The chemical composition of which was Mg-3\%A1-1\%Zn-0.3\%Mn. The homogenization for the as-cast billets was conducted at $400{ }^{\circ} \mathrm{C}$ for $12 \mathrm{~h}$ and followed by water quenching. The rectangular samples were machined from the homogenized ingot with a starting dimension of $40 \mathrm{~mm} \times 35 \mathrm{~mm} \times 35 \mathrm{~mm}$. The samples were heated in a muffle furnace at $300{ }^{\circ} \mathrm{C}$ for 5 min before forging. Multiple forging was carried out along three orthogonal directions in turn by an air hammer, and the strain rate was about 100/s. Shown in Figure 1 is the schematic drawing of the multiple direction forging (MDF) process. In the first pass, the initial forging direction was normal to face $\mathrm{A}$, and in the following pass, the forging direction was normal to face $B$, then the forging direction was normal to face $C$ in the third pass. The true strain was calculated as $\ln \left(h_{0} / h_{1}\right)$, where $h_{0}$ and $h_{1}$ represent the initial height and final height at each forging passes respectively. To investigate the effect of pass strain on microstructure, texture and mechanical properties during HSRMF, 6 passes were employed with 4 different pass strains $(\Delta \varepsilon=0.1$, $0.16,0.22$ and 0.35$)$. Microstructures analysis was carried out at the central part of the specimens perpendicular to the forging direction (FD) by using electron back-scatter diffraction (EBSD). EBSD observation was conducted on a Zeiss EVO18 SEM equipped (Hengyang, China) with an HKL-EBSD system (Hengyang, China) and operated at $20 \mathrm{kV}$, and the step size for measurement was $1.5 \mu \mathrm{m}$. The Schultz reflection method by X-ray diffraction was used to characterize the texture. The dog-bone shaped tensile specimens were machined form the alloys forged to 6 passes, and the gauge length was $10 \mathrm{~mm}$. The specimen was tested under constant speed of $0.5 \mathrm{~mm} / \mathrm{min}$ with the tensile direction paralleling to RD at room temperature.

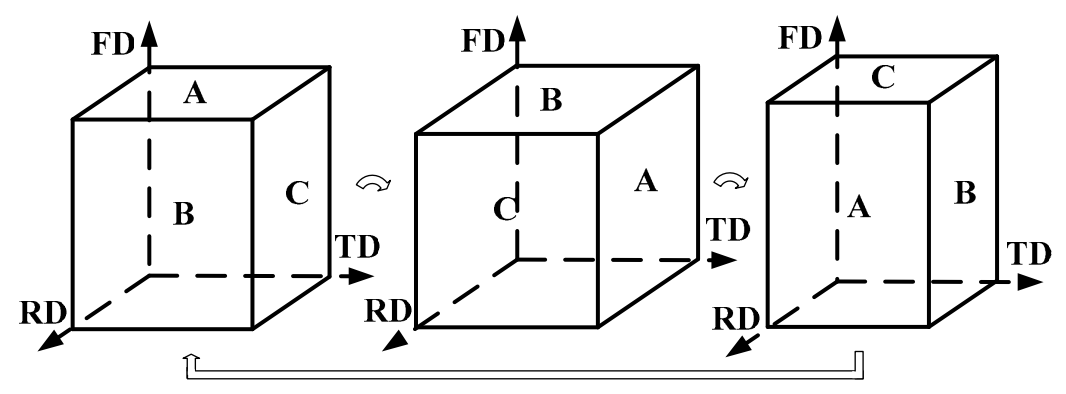

Figure 1. Schematic drawings and axis definition of the high strain rate multiple forging (HSRMF) process. 


\section{Results and Discussion}

\subsection{Microstructure}

In order to analyze the boundary evolution of the grain and twin during HSRMF, misorientation angle distributions at different accumulated strains with a pass strain of $\Delta \varepsilon=0.22$ were characterized by EBSD, as shown in Figure 2. It is observed from the EBSD results that the boundary with low angles $\left(<5^{\circ}\right)$ were significantly affected by the polishing state compared to the boundaries with higher angles, therefore, the boundaries with misorientation angles higher than $5^{\circ}$ were taken into consideration in the present study. As shown in Figure 2a, four peaks were found in the misorientation distribution map around $8^{\circ}, 38^{\circ}, 64^{\circ}$ and $86^{\circ}$ as the accumulated strain of $\sum \Delta \varepsilon=0.22$, and the maximum peak of the boundary misorientation was located around $86^{\circ}$. As the accumulated strain increased to $\sum \Delta \varepsilon=0.44$, three peaks were observed around $8^{\circ}, 38^{\circ}$ and $86^{\circ}$, and the number fraction increased around $38^{\circ}$ while it decreased around $86^{\circ}$ compared to the previous forging pass (Figure $2 \mathrm{~b}$ ). With the increasing strain, the maximum peak shifted from $86^{\circ}$ to the other location, and the peaks around $38^{\circ}$ were much weaker (Figure 2c). The boundary misorientation became randomly distributed at an accumulated strain of $\sum \Delta \varepsilon=1.32$, and most of the peaks that occurred at lower accumulated strains disappeared (Figure 2d).

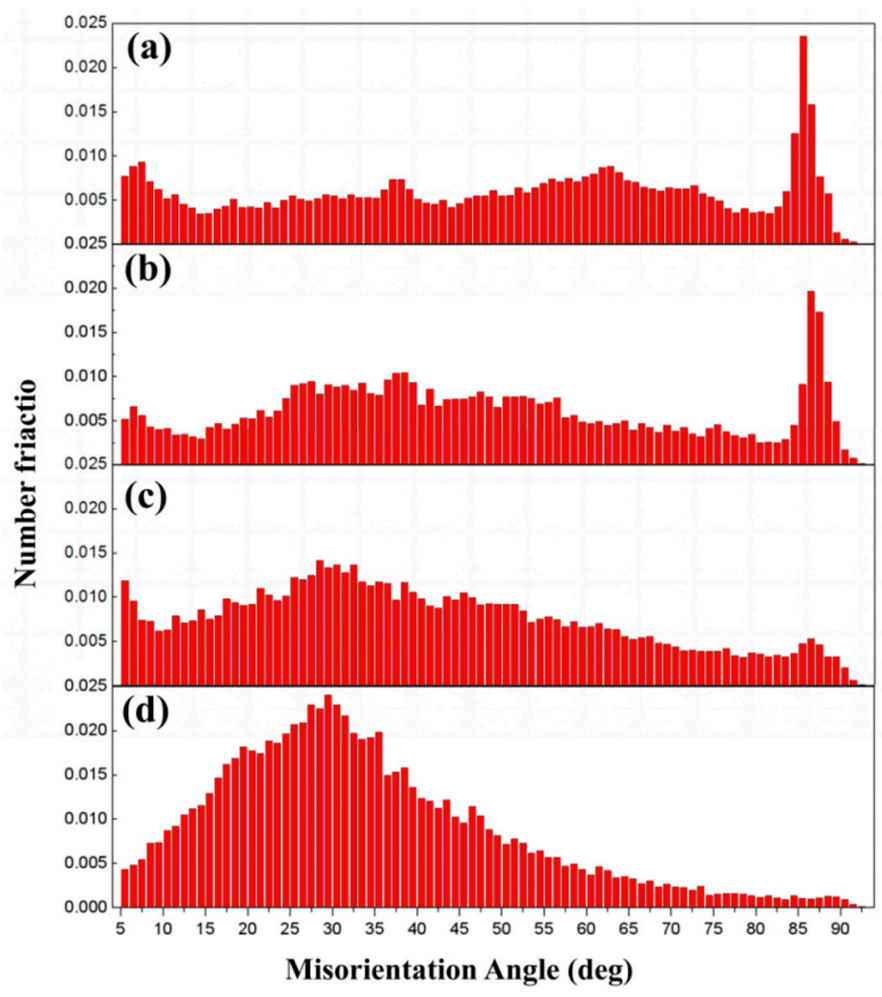

Figure 2. Number fraction of the misorientation in AZ31 alloys HSRMFed to different accumulated strain with pass strains of $\Delta \varepsilon=0.22$ (a) 0.22 , (b) 0.44 , (c) 0.88 and (d) 1.32 .

Figure 3 shows the inverse pole figures (IPF) and boundary misorientation maps of AZ31 alloys HSRMFed to different accumulated strains with pass strain of $\Delta \varepsilon=0.22$. The $\{101(-) 2\},\{101(-) 3\}$, $\{101(-) 1\}$ and $\{101(-) 1\}-\{101(-) 2\}$ twins were found with high density, and the twins divided the initial coarse grains into finer twin platelets. Meanwhile, dynamic recrystallization (DRX) developed at twins and grain boundaries, and a large amounts of DRX grains can be observed as the accumulated strain of $\sum \Delta \varepsilon=0.22$. The twin density decreased while DRX fraction increased as the accumulated strain increased. The fraction of $\{101(-) 3\}$ and $\{101(-) 1\}$ contraction twin decreased as the accumulated strain increased to $\sum \Delta \varepsilon=0.44$ and 0.88 , however a large amount of $\{101(-) 2\}$ extension twin and $\{101(-) 1\}-\{101(-) 2\}$ secondary twin could also be observed. When the $\sum \Delta \varepsilon=1.32$, no twin was detected 
and a full recrystallized structure was achieved, and the average grain size was $8.21 \mu \mathrm{m}$ with a standard deviation of $2.42 \mu \mathrm{m}$. The frequency of the small DRX grains $(<10 \mu \mathrm{m})$ was about $53 \%$ while the frequency of the large DRX grains $(>15 \mu \mathrm{m})$ was about $7 \%$.
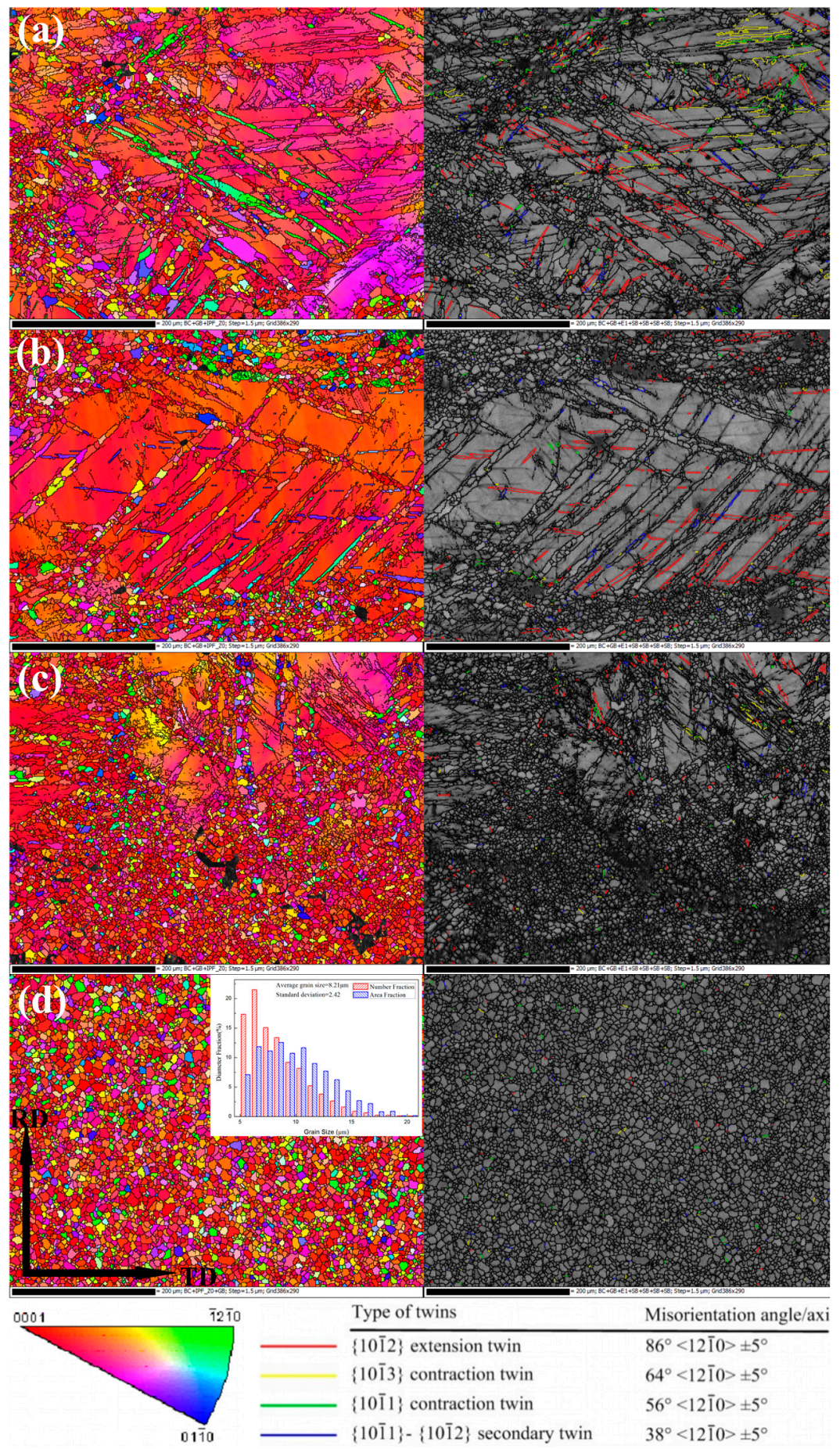

Figure 3. Inverse pole figures and boundary misorientation maps of AZ31 alloys HSRMFed to different accumulated strains with pass strain of $\Delta \varepsilon=0.22$ (a) 0.22 , (b) 0.44 , (c) 0.88 and (d) 1.32 .

According to the description above, it was confirmed that the local peaks around $38^{\circ}, 64^{\circ}$ and $86^{\circ}$ could be ascribed to the $\{101(-) 1\}-\{101(-) 2\}$ secondary twin, $\{101(-) 3\}$ contraction twin and $\{101(-) 2\}$ extension twin, respectively. The peaks around $38^{\circ}$ and $86^{\circ}$ were detected in all of the alloys before 
full recrystallized, therefore $\{101(-) 2\}$ and $\{101(-) 1\}-\{101(-) 2\}$ twining are the predominant twinning at the early forging pass of HSRBF. Zhu et al. [21] and Li et al. [22] have reported similar results about high strain rate deformation of magnesium alloys. Moreover, a certain number of DRX grains were found within the twinned regions and at grain boundaries. Owing to the high density of deformation twins forming at high strain rates, we could infer that DRX within twins was dominant during HSRBF. It is acknowledged that twinning induced DRX (TDRX) is the DRX mechanism within twins, and twin boundaries can impede the dislocation motion and provide the driving force for DRX, as a result, the grains in magnesium alloys are significantly refined $[23,24]$. Therefore, the formation of high density twins and subsequently TDRX were the main reasons for the grain refinement of AZ31 alloy in the present study.

Shown in Figure 4 is the inverse pole figure maps and grain size distributions of alloys HSRMFed to 6 pass with different pass strains. An incomplete DRXed structure with inhomogeneous DRX grains was observed in the alloy HSRMFed to 6 pass with pass strain of $\Delta \varepsilon=0.1$. The average grain size was $10.4 \mu \mathrm{m}$ with a standard deviation of $4.65 \mu \mathrm{m}$. The frequency of the small DRX grains $(<10 \mu \mathrm{m})$ was about $22 \%$ while the frequency of the large DRX grains ( $>15 \mu \mathrm{m})$ was about $48 \%$, and some unDRXed regions were detected. The structure of the alloy HSRMFed to 6 pass with a pass strain of $\Delta \varepsilon=0.16$ was similar to the alloy HSRMFed to 6 pass with a pass strain of $\Delta \varepsilon=0.22$. A full recrystallized structure with an average grain size of $7.82 \mu \mathrm{m}$ was detected as shown in Figure $4 \mathrm{~b}$, and the corresponding standard deviation was $2.09 \mu \mathrm{m}$. The frequency of the small DRX grains $(<10 \mu \mathrm{m})$ was about $53 \%$ while the frequency of the large DRX grains $(>15 \mu \mathrm{m})$ was about $7 \%$. Inhomogeneous DXR grains were detected in the full recrystallized alloy HSRMFed to 6 pass with a pass strain of $\Delta \varepsilon=0.33$ as can be seen in Figure 4c, and about 45\% of the grains were finer than $10 \mu \mathrm{m}$ while some of the grains grew to 30-60 $\mu \mathrm{m}$. The average grain size was $10.4 \mu \mathrm{m}$ with a standard deviation of $3.81 \mu \mathrm{m}$. As mentioned above, the microstructure of the alloys HSRMFed to 6 passes with different pass strains were quite different, i.e., homogeneous structures were obtained at a medium pass strain $(\Delta \varepsilon=0.16-0.22)$ while inhomogeneous structures were formed at a lower $(\Delta \varepsilon=0.1)$ or higher $(\Delta \varepsilon=0.35)$ pass strain.

To analyze the effect of pass strain on the microstructure during HSRMF, the alloys HSRMFed with pass strains of $\Delta \varepsilon=0.1$ and 0.35 were tested by EBSD. As can be seen in Figure 5 , both twins and DRX grains were observed in the alloys HSRMFed with pass strains of $\Delta \varepsilon=0.1$. However, both the twin lamellae and DRX grain sizes of the alloy HSRMFed with pass strains of $\Delta \varepsilon=0.1$ were much coarser than those of the alloy HSRMFed with higher pass strains. In other words, the grain refinement of HSRMF with a lower pass strain $(\Delta \varepsilon=0.1)$ was less extensively compared to larger pass strains $(\Delta \varepsilon=0.16-0.22)$. As can be seen in Figure 6a, a homogeneous DXR structure with an average grain size of $8.1 \mu \mathrm{m}$ was obtained in the alloy HSRMFed to the accumulated strain of $\sum \Delta \varepsilon=1.4$ with a pass strain of $\Delta \varepsilon=0.35$, and the related standard deviation was $2.44 \mu \mathrm{m}$. The grain size distribution was similar to that of the alloys HSRMFed to 6 pass with a medium pass strain $(\Delta \varepsilon=0.16-0.22)$, and the frequency of the small DRX grains $(<10 \mu \mathrm{m})$ was about $54 \%$ while the frequency of the large DRX grains $(>15 \mu \mathrm{m})$ was about $10 \%$. With an increase of the accumulated strain in the alloys HSRMFed with a higher pass strain $(\Delta \varepsilon=0.35)$, an abnormal grain growth developed as shown in Figure $6 \mathrm{~b}$, and most of the grains were finer than $20 \mu \mathrm{m}$ while some of the grains grew to more than $30 \mu \mathrm{m}$. The average grain size was $9.1 \mu \mathrm{m}$ with a standard deviation of $3.75 \mu \mathrm{m}$. 

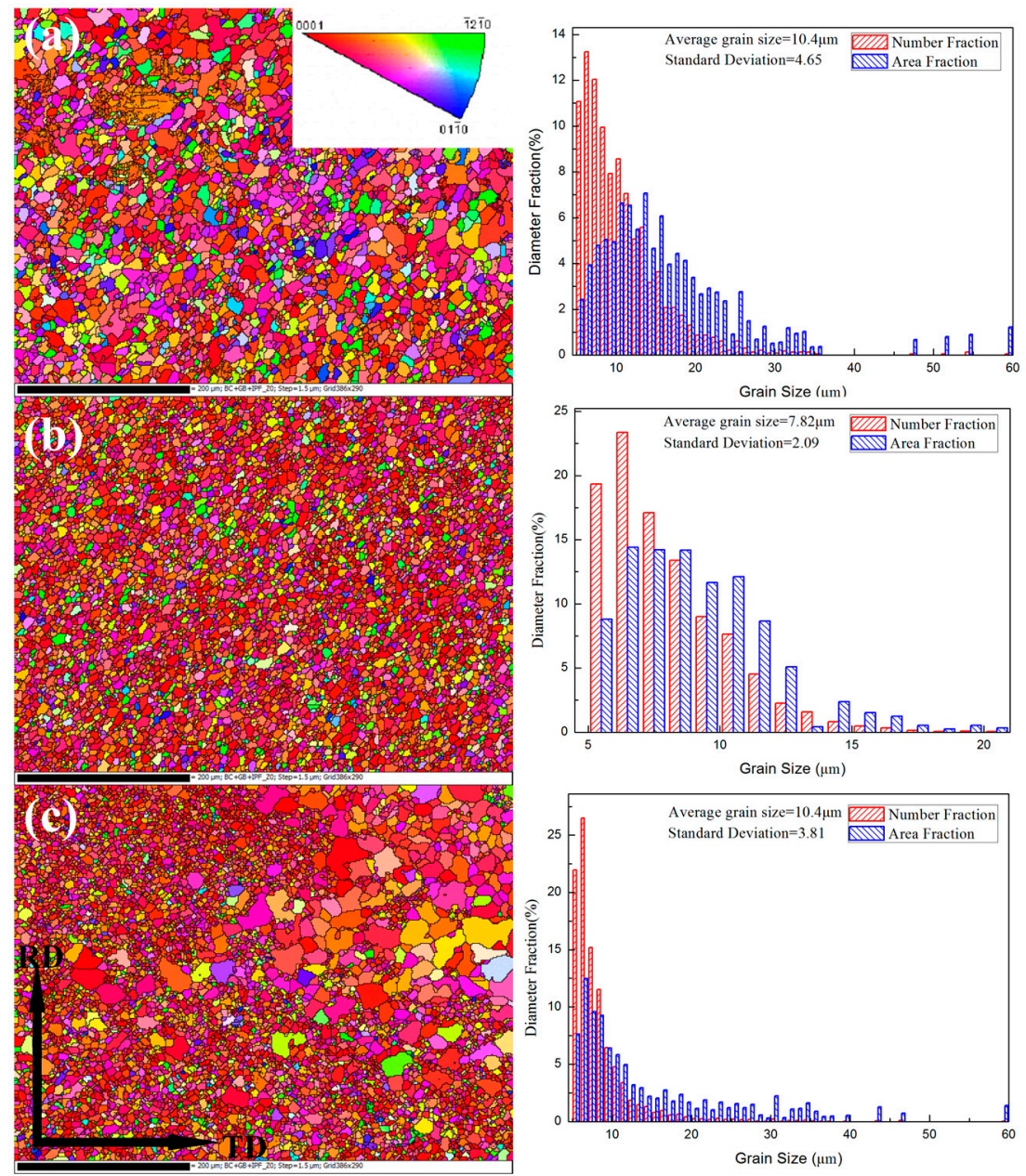

Figure 4. Electron back-scatter diffraction (EBSD) results of AZ31 alloys HSRMFed to 6 passes with different pass strains and accumulated strain: (a) 0.1/0.6, (b) 0.16/0.96 and (c) 0.35/2.1.

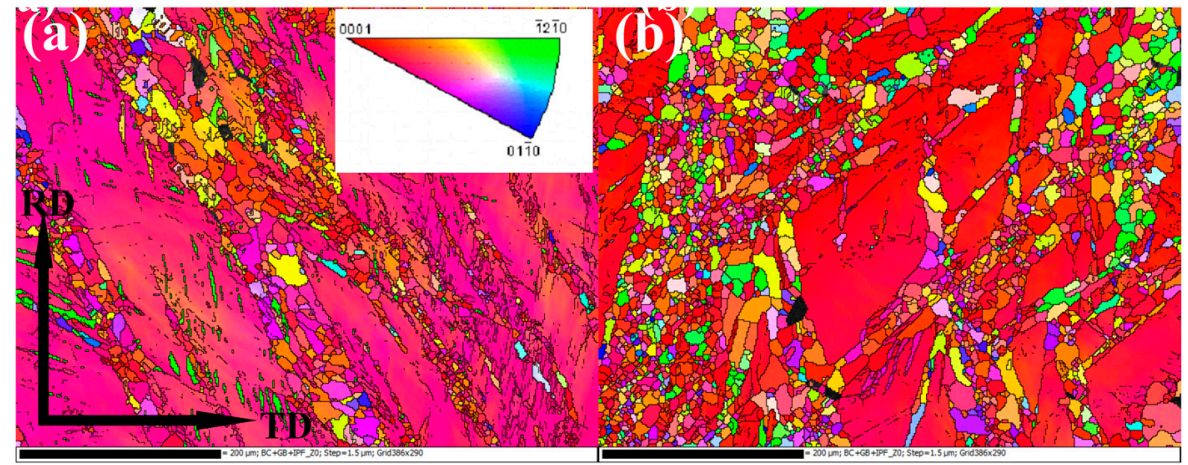

Figure 5. Inverse pole figures ofAZ31 alloys HSRMFed to different accumulated strain with a pass strain of $\Delta \varepsilon=0.1$, (a) 0.2 and (b) 0.3 . 

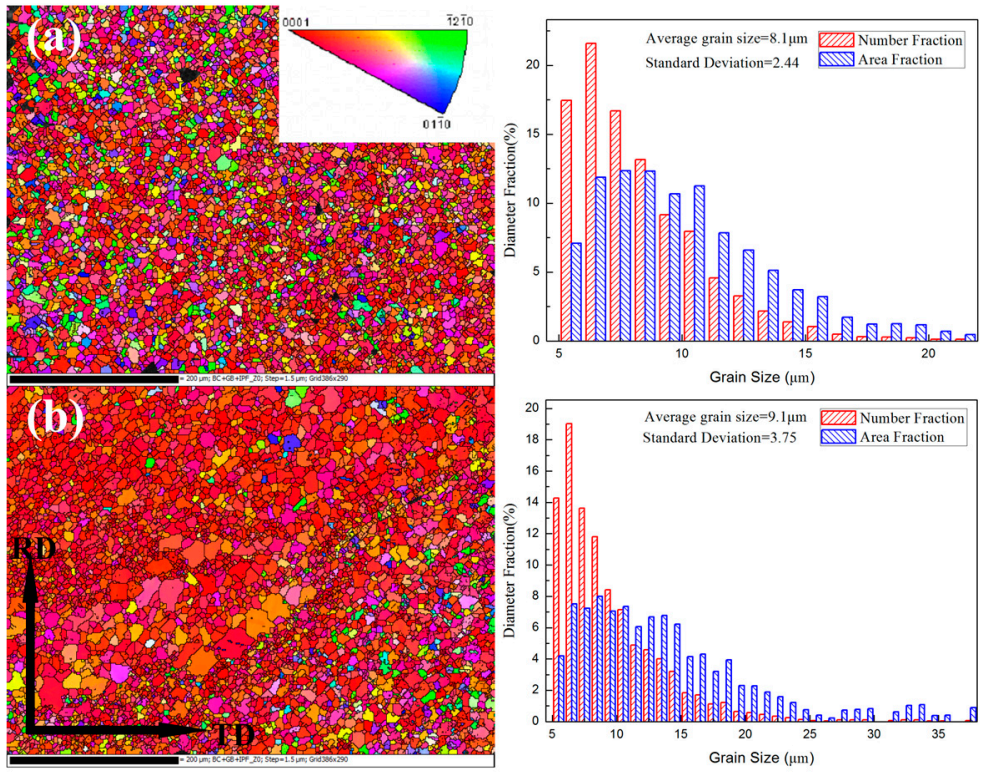

Figure 6. EBSD results of AZ31 alloys HSRMFed to different accumulated strain with a pass strain of $\Delta \varepsilon=0.35$, (a) 1.4 and (b) 1.75 .

As discussed above, the effect of the pass strain on microstructure during HSRMF in this research could be concluded as follows. Firstly, the DRX grain of the alloy HSRMFed with a lower pass strain $(\Delta \varepsilon=0.1)$ was coarser than that of the alloys HSRMFed alloys with higher pass strains $(\Delta \varepsilon=0.16-0.35)$. In TDRX, the DRX grain size was obviously dependent upon the thickness of twin lamellae, and the DRX grain size increased with the twin lamellae thickness $\lambda$ [25]. Formation of stable twins generally comprises of nucleation of twin embryos and their subsequent growth, and the growth rates of the twin embryos should be approximately similar under the same deformation conditions [26]. Therefore, the twin lamellae thickness $\lambda$ is related to the critical twin nucleus thickness $\lambda_{0}$, which can be expressed as follows [27]:

$$
\lambda_{0}=\frac{\mathrm{G} \gamma_{\mathrm{TB}}}{\sigma 2}
$$

where $G$ and $\gamma_{\text {Тв }}$ are the shear modulus and the twin boundary energy, respectively. $\sigma$ is the driving stress that can be taken as the stress at the pileup tip at the boundary between neighboring grains, which will increase with strain. Since $\lambda_{0}$ is inversely proportional to $\sigma^{2}$, the critical twin nucleus thickness would decrease significantly with increasing strain in theory. Therefore, a lower pass strain $(\Delta \varepsilon=0.1)$ during HSRMF may result in higher critical twin nucleus thickness, and consequently result in less sensitive grain refinement. It was interesting to find that a similar homogeneous DXR structure could be detected in alloys HSRMFed at a higher pass strain $(\Delta \varepsilon=0.16-0.35)$, implying that similar twin lamellae thickness were obtained with increasing of the pass strain. The same results have been reported by Xiao et al. [26] and Yan et al. [28], the twin lamellae thickness will be saturated as the deformation strain is obtined to some extent. Secondly, the DRX extent of the alloy HSRMFed with a lower pass strain $(\Delta \varepsilon=0.1)$ was less sensitive than those of the alloys HSRMFed with higher pass strains $(\Delta \varepsilon=0.16-0.35)$. DRX was more difficult to initiate at the regions without twins during TDRX, and consequently resulted in island structures without DRX, which were surrounded by DRXed grains [29]. Therefore, the development of an incomplete DRXed structure (Figure 4a) was owing to the thicker twin lamellae and lower twin density in the alloy HSRMFed with a lower pass strain $(\Delta \varepsilon=0.1)$, while a full recrystallized structure (Figures $3 \mathrm{~d}$ and $4 \mathrm{~b}, \mathrm{c})$ was achieved due to the saturated twin lamellae thickness and higher twin density in the alloys HSRMFed alloys with higher pass strains $(\Delta \varepsilon=0.16-0.35)$. Thirdly, homogeneous DRX structure will become inhomogeneous due to abnormal grain growth as the accumulated strain exceeds 1.4. The ratio of $D / d$ (where $D$ is the largest grain diameter and $d$ is the average grain diameter) increased from 3 to 6 as the accumulatd strain 
ranged from 1.4 to 2.1, indicating obviously grain growth. Abnormal grain growth was always in terms of secondary recrystallization because only a few grains grow rapidly and consume the rest of the microstructure, which has been widely reported in the magnesium alloy annealed for a long period [30-32]. During HSRMF, both plastic work and frictional work converts into heat, and there will be less heat loss due to the short deformation time, thus the adiabatic heating condition is obtained, which may lead to the increment of temperature. It was reported that the deformation temperature was much higher than the heat temperature of the forgings when the forging strain rate went beyond 10/s [33]. Therefore, the temperature of the forged alloys was higher than $300{ }^{\circ} \mathrm{C}$, where secondary recrystallization may be activated. It was interesting to find that the time for grain growth in the present study is much more limited compared to Reference [30-32], and the recrystallization mechanism was unclear and worthy of further research.

\subsection{Texture}

The (0002) pole figures of the AZ31 alloy HSRMFed to 6 pass with different pass strains are shown in Figure 7. As can be seen in Figure 7a, a double peak texture characteristic of axisymmetric pole figures was detected in the alloy HSRMFed with a pass strain of $\Delta \varepsilon=0.1$, and the intensity maximum rotated to RD away from the center of the pole figure. The texture intensity increased as the pass strain, and pole figure became unsymmetric with intensity maximum rotated to the rolling direction (RD). Typical rolling texture with a circle-shaped distribution of $\{0002\}$ orientation was obtained in the alloy HSRMFed with a pass strain of $\Delta \varepsilon=0.22$ and 0.35 as illustrated in Figure 7c,d. However the basal poles split about $30^{\circ}$ and $20^{\circ}$ from the center of the pole figure in the alloy HSRMFed with a pass strain of $\Delta \varepsilon=0.22$ and 0.35 respectively, implying that the inclination of the basal pole from forging direction (FD) decreased as the pass strain increased. Due to the limited slip systems in hexagonal crystal (HCP) structure, strong texture always exists in the wrought magnesium alloy after plastic deformation. Many efforts have been done on texture weakening, both titled texture [34] and double peak texture [35] were reported to weaken textures and results in better formability. It was worthy to note that titled texture or double peak texture could be achieved in the AZ31 alloy HSRMFed with a pass strain ranging from 0.1 to 0.35 .

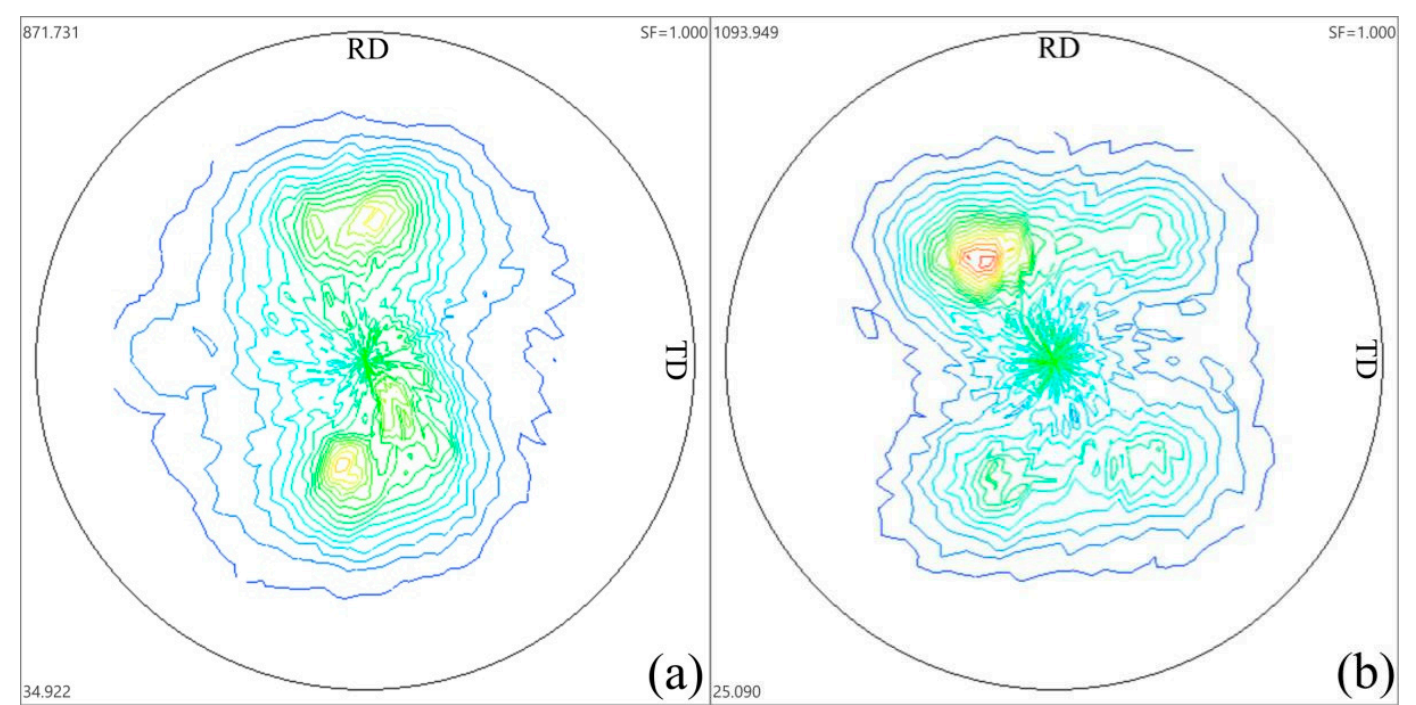

Figure 7. Cont. 


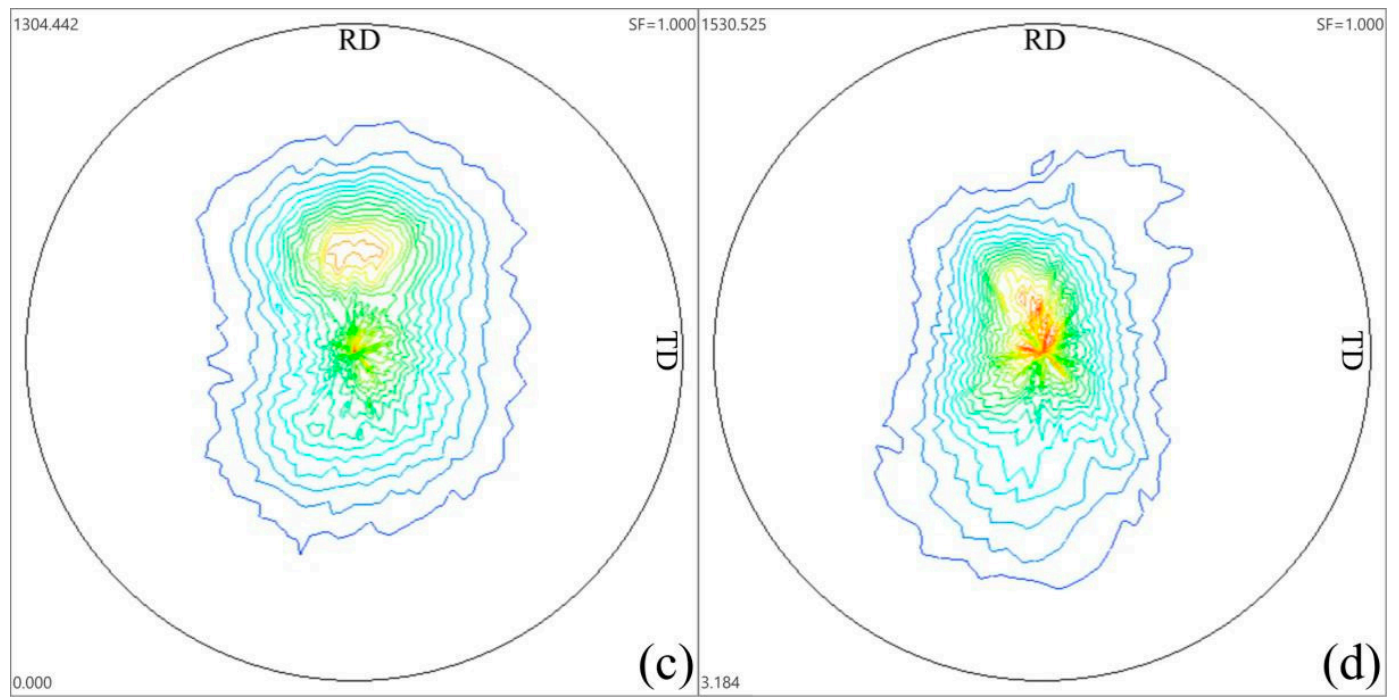

Figure 7. Pole figure detected by XRD in AZ31 alloys HSRMFed to 6 pass with different pass strains (a) 0.1, (b) 0.16, (c) 0.22 and (d) 0.35 .

\subsection{Mechanical Properties}

The mechanical properties of the alloys HSRMFed to 6 pass with different pass strains are shown in Figure 8, and the tensile data is listed in Table 1, containing yield strength (YS) $\sigma_{\mathrm{S}}$, ultimate tensile strength (UTS) $\sigma_{\mathrm{b}}$ and elongation $\delta$. As can be seen in Figure 8 and Table 1, both of the strength and elongation increased with a pass strain as $\Delta \varepsilon<0.16$ while decreased with the pass strain increasing as $\Delta \varepsilon>0.16$. An excellent combination of mechanical properties with the ultimate tensile strength (UTS) of $328 \mathrm{MPa}$ and elongation of $30 \%$ was achieved in the alloy HSRMFed to 6 pass with a pass strain of $\Delta \varepsilon=0.16$.

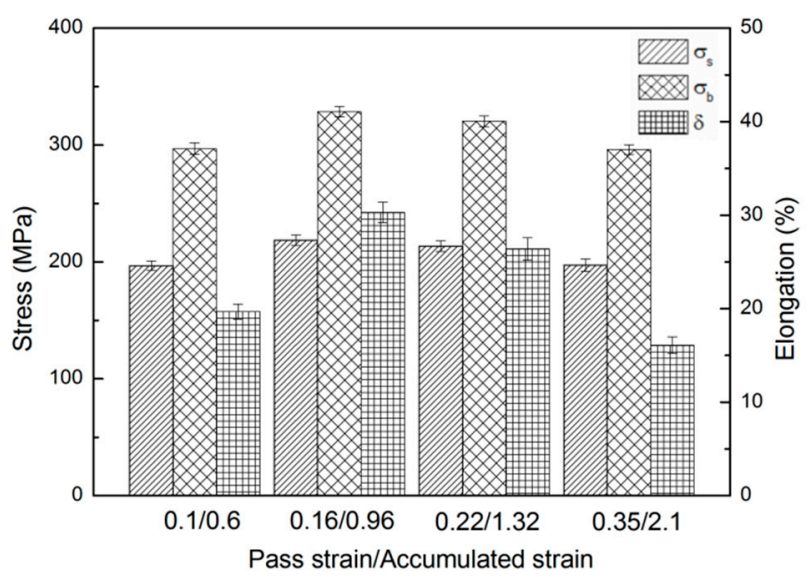

Figure 8. Mechanical properties of AZ31 alloys HSRMFed to 6 pass with different pass strains and accumulated strains.

Table 1. Mechanical properties of AZ31 alloy HSRMFed 6 pass with different pass strains and accumulated strains.

\begin{tabular}{cccc}
\hline Pass strain/Accumulated Strain & $\boldsymbol{\sigma}_{\mathbf{s}} \mathbf{( M P a )}$ & $\boldsymbol{\sigma}_{\mathbf{b}}(\mathbf{M P a})$ & $\boldsymbol{\delta}(\mathbf{\%})$ \\
\hline $0.1 / 0.6$ & 196.7 & 296.9 & 19.7 \\
$0.16 / 0.96$ & 218.5 & 328.5 & 30.3 \\
$0.22 / 1.32$ & 213.5 & 320.3 & 26.4 \\
$0.35 / 2.1$ & 197.2 & 296.1 & 16.1 \\
\hline
\end{tabular}


In combination with the microstructure discussed above, the grain refinement may attribute to the variation of strength. According to the Hall-Petch equation, grain refinement results in a strength increase because of grain boundary strengthening [36]. The average grain sizes were 10.4, 7.8, 8.2 and $10.4 \mu \mathrm{m}$ for the alloys HSRMFed to 6 pass with a pass strain of $0.1,0.16,0.22$ and 0.35 respectively, therefore the strength increased with a pass strain of $\Delta \varepsilon<0.16$ while it decreased with a pass strain of $\Delta \varepsilon>0.16$.

The Schmid factor distribution of the $\{0001\}<112(-) 0>$ basal slip along RD in alloys HSRMFed with different pass strains are shown in Figure 9. As can be seen in Figure 9, the average Schmid factor decreased with a pass strain, which was consistent with the texture discussed above. In theory, the ductility increases with Schmid factor because of the greater possibility of the activation of more slip [37]. However, the alloys HSRMFed with a lower pass strain $(\Delta \varepsilon=0.1)$ showed relatively poor ductility although it had the highest average Schmid factor. The incomplete DRX structure and less sensitive grain refinement as shown in Figure 4a might lead to the relative poor ductility. In contrast, the alloys HSRMFed with medium pass strains $(\Delta \varepsilon=0.16-0.22)$ showed relatively higher ductility in spite of a lower average Schmid factor, and the homogeneous fine DRX grain structure as shown in Figures $3 \mathrm{~d}$ and $4 \mathrm{~b}$ might be responsible for this phenomenon. The highest ductility with an elongation of $30 \%$ was achieved in the alloy HSRMFed with a pass strain of $\Delta \varepsilon=0.16$, which might result from the combination relative higher average Schmid factor and homogeneous fine DRX structure.
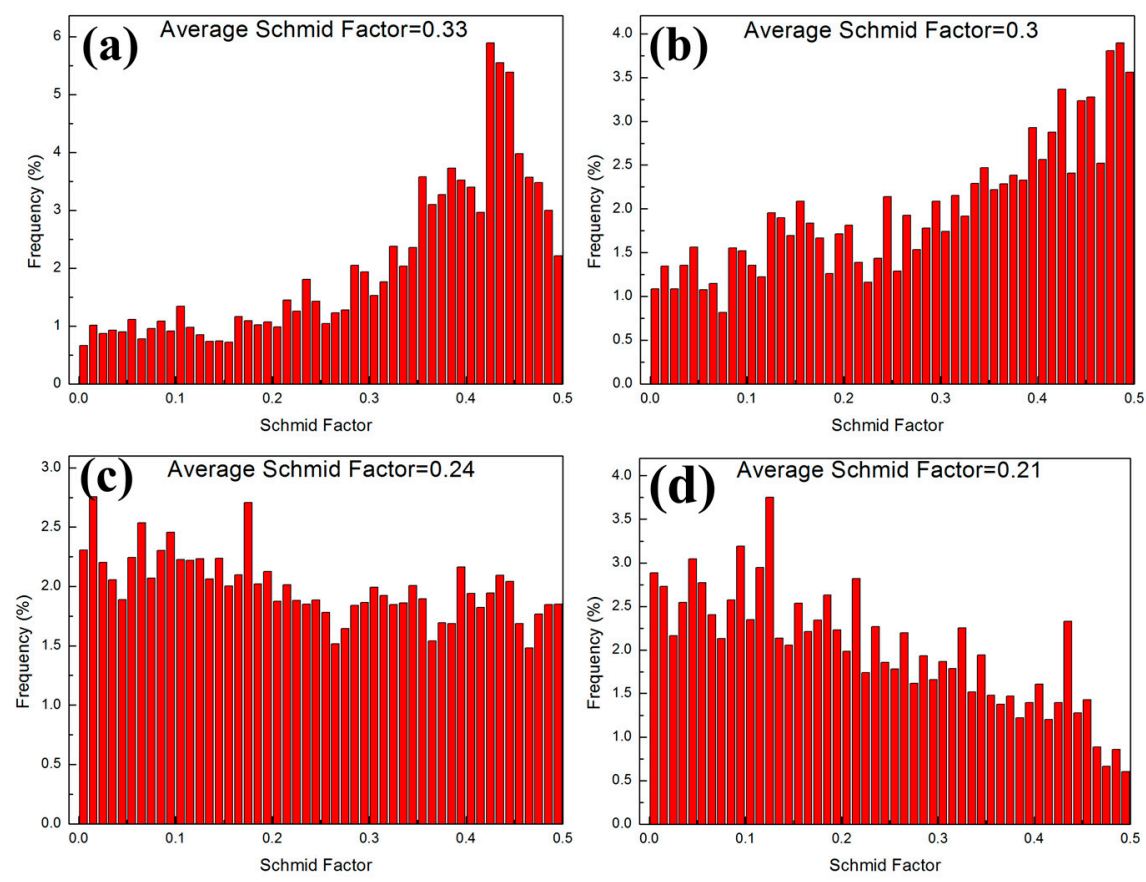

Figure 9. Schmid factor distribution of $\{0001\}<112(-) 0>$ basal slip along rolling direction (RD) in alloys HSRMFed with different pass strains (a) 0.1 , (b) 0.16 , (c) 0.22 and (d) 0.35 .

Figure 10 shows the tensile fracture images for alloys HSRMFed to 6 pass with different pass strains. As shown in Figure 10a,d, a typical quasi-cleavage was observed in the alloys HSRMFed with a pass strain of $\Delta \varepsilon=0.1$ and 0.35 . A number of dimples were found at the fracture surface, while tearing ridges and cleavage steps were found with low quantity. The fracture of the alloy HSRMFed with medium pass strains $(\Delta \varepsilon=0.16-0.22)$ are characteristic of excellent ductility, and no obvious tearing ridge could be found on the fracture surface, and the entire sample was covered by large amount of dimples, as shown in Figure 10b,c. The dimples in the alloy HSRMFed with a pass strain of $\Delta \varepsilon=0.16$ were deeper and larger than that of the alloy HSRMFed with a pass strain of $\Delta \varepsilon=0.22$, indicating better ductility was achieved in the alloy HSRMFed with a pass strain of $\Delta \varepsilon=0.16$. Take the 
mechanical properties given in Figure 8 and Table 1 into consideration, the fracture images were in good agreement with the ductility.
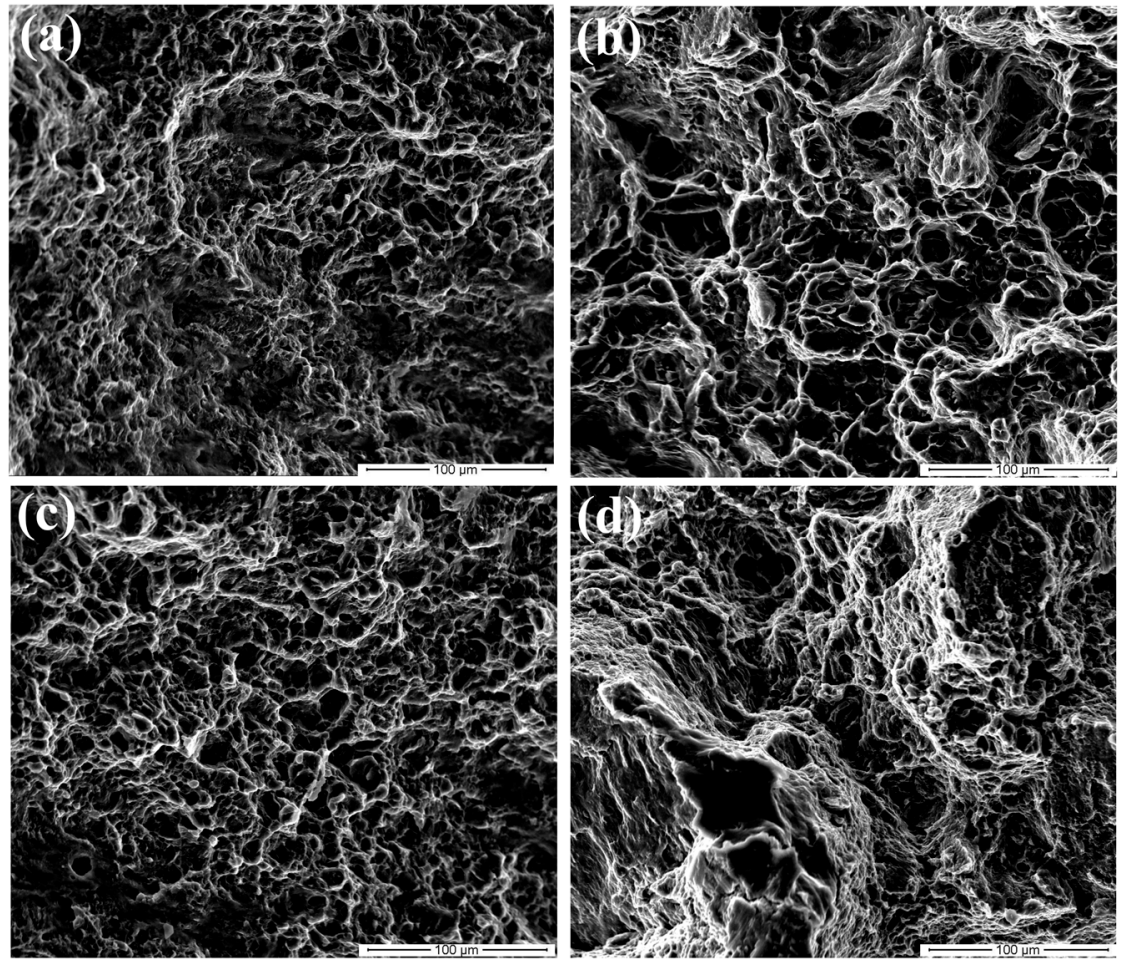

Figure 10. SEM images of tensile fracture for samples HSRMFed with different pass strains (a) 0.1,

(b) 0.16, (c) 0.22 and (d) 0.35 .

As discussed above, the pass strain during HSRMF is one of the determined factors that are relative to the mechanical properties of the HSRMFed alloys. The homogeneous fine DRX structure with a weak texture could be developed to achieve high strength and ductility in the HSRMFed alloy. Therefore, a pass strain of $\Delta \varepsilon>0.16$ was recommended to develop a saturated twin lamellae thickness that will consequently result in a fine DRX grain size, and the pass strain should not exceed 0.35 to avoid extensive basal texture. Moreover, the accumulated strain of $\sum \Delta \varepsilon>0.96$ was recommended to achieve sufficient DRX in the alloy, and the accumulated strain should not exceed 1.4 to prevent secondary recrystallization. In summary, in order to fabricate HSRMFed AZ31 alloy with high strength and ductility, the optimum pass strain and accumulated strain range were $0.16-0.35$ and $0.96-1.4$ respectively.

\section{Conclusions}

Six passes of high strain rate multiple forging (HSRMF) was carried out on the AZ31 alloy with a pass strain ranging from 0.1 to 0.35 . The microstructure, texture and mechanical properties of the HSRMFed alloy were examined. The main conclusions were listed below.

1. The initial grain can be rapidly refined during HSRMF ascribing to the special mechanism including the formation of high density $\{101(-) 2\}$ and $\{101(-) 1\}-\{101(-) 2\}$ twins and subsequently twining induced DRX, and the grain refinement of the HSRMFed alloy was determined by the twin lamellae thickness.

2. Lower pass strain $(\Delta \varepsilon=0.1)$ during HSRMF led to thick twin lamellae and consequently results in coarser DRX grain, meanwhile, an incomplete DRX occurred. While the twin lamellae thickness decreased with increasing pass strain, the saturated twin lamellae thickness was achieved in alloys HSRMFed with a higher pass strain $(\Delta \varepsilon=0.16-0.35)$ and resulted in a fine DRX structure. 
3. Double peak texture and titled texture can be achieved in the AZ31 alloy HSRMFed with a pass strain of $\Delta \varepsilon<0.16$ and $\Delta \varepsilon>0.16$ respectively, and the texture intensity increased with the pass strain.

4. In order to fabricate the HSRMFed AZ31 alloy with high strength and ductility, the optimum pass strain range was $0.16-0.35$ to achieve a weak texture and extensive grain refinement, and an accumulated strain range of $\sum \Delta \varepsilon=0.96-1.4$ was recommended to develop sufficient DRX and prevent secondary recrystallization.

Author Contributions: Conceptualization, Y.W.; data curation, B.D. and Z.N.; formal analysis, X.Z.; funding acquisition, Y.W.; investigation, T.Y. and W.L.; project administration, Y.W.; resources, X.Z. and T.Y.; writing-original draft, Y.W.; writing-review and editing, Y.W. All authors have read and agreed to the published version of the manuscript.

Funding: The research described in this paper was supported by National Natural Science Foundation Project of China (51501061), Natural Science Foundation of Hunan Province (2019JJ30009), Key Scientific Research Fund of Hunan Provincial Education Department of China (18A423).

Conflicts of Interest: The authors declare no conflict of interest.

\section{References}

1. Tekumalla, S.; Gupta, M.; Almajid, A.; Gupta, M. Mechanical Properties of Magnesium-Rare Earth Alloy Systems: A Review. Metals 2014, 5, 1-39. [CrossRef]

2. Rao, K.P.; Prasad, Y.V.R.K.; Dzwończyk, J.; Hort, N.; Kainer, K.U. Hot Deformation Mechanisms in AZ31 Magnesium Alloy Extruded at Different Temperatures: Impact of Texture. Metals 2012, 2, 292-312. [CrossRef]

3. Zhu, S.; Yan, H.; Chen, J.; Wu, Y.; Su, B.; Du, Y.; Liao, X. Feasibility of high strain-rate rolling of a magnesium alloy across a wide temperature range. Scr. Mater. 2012, 67, 404-407. [CrossRef]

4. Zhu, S.-Q.; Yan, H.; Chen, J.; Wu, Y.; Du, Y.; Liao, X. Fabrication of Mg-Al-Zn-Mn alloy sheets with homogeneous fine-grained structures using high strain-rate rolling in a wide temperature range. Mater. Sci. Eng. A 2013, 559, 765-772. [CrossRef]

5. Alaneme, K.K.; Okotete, E.A. Enhancing plastic deformability of Mg and its alloys-A review of traditional and nascent developments. J. Magnes. Alloy. 2017, 5, 460-475. [CrossRef]

6. Miura, H.; Yu, G.; Yang, X. Multi-directional forging of AZ61Mg alloy under decreasing temperature conditions and improvement of its mechanical properties. Mater. Sci. Eng. A 2011, 528, 6981-6992. [CrossRef]

7. Verma, R.; Nath, S.K.; Jayaganthan, R. Effect of high strain rolling and multiple forging on tensile and fracture behavior of ZE41 magnesium alloy. Mater. Today Process. 2018, 5, 17195-17202. [CrossRef]

8. Jamali, A.; Mahmudi, R. Evolution of microstructure, texture, and mechanical properties in a multi-directionally forged ZK60 Mg alloy. Mater. Sci. Eng. A 2019, 752, 55-62. [CrossRef]

9. Biswas, S.; Suwas, S. Evolution of sub-micron grain size and weak texture in magnesium alloy Mg-3Al-0.4Mn by a modified multi-axial forging process. Scr. Mater. 2012, 66, 89-92. [CrossRef]

10. Salandari-Rabori, A.; Zarei-Hanzaki, A.; Abedi, H.; LeComte, J.; Khatami-Hamedani, H. Micro and macro texture evolution during multiaxial forging of a WE43 magnesium alloy. J. Alloy. Compd. 2018, 739, $249-259$. [CrossRef]

11. Jiang, M.; Yan, H.; Chen, R. Twinning, recrystallization and texture development during multi-directional impact forging in an AZ61 Mg alloy. J. Alloy. Compd. 2015, 650, 399-409. [CrossRef]

12. Jiang, M.; Yan, H.; Chen, R. Microstructure, texture and mechanical properties in an as-cast AZ61 Mg alloy during multi-directional impact forging and subsequent heat treatment. Mater. Des. 2015, 87, 891-900. [CrossRef]

13. Jiang, M.; Yan, H.; Chen, R. Enhanced mechanical properties due to grain refinement and texture modification in an AZ61 Mg alloy processed by small strain impact forging. Mater. Sci. Eng. A 2015, 621, $204-211$. [CrossRef]

14. Shah, S.; Wu, D.; Chen, R.; Song, G. Static recrystallization behavior of multi-directional impact forged Mg-Gd-Y-Zr alloy. J. Alloy. Compd. 2019, 805, 189-197. [CrossRef]

15. Wu, Y.-Z.; Yan, H.-G.; Chen, J.-H.; Zhu, S.-Q.; Su, B.; Zeng, P.-L. Microstructure and mechanical properties of ZK60 magnesium alloy fabricated by high strain rate multiple forging. Mater. Sci. Technol. 2013, 29, 54-59. [CrossRef] 
16. Wu, Y.-Z.; Yan, H.-G.; Chen, J.; Du, Y.-G.; Zhu, S.-Q.; Su, B. Microstructure and mechanical properties of ZK21 magnesium alloy fabricated by multiple forging at different strain rates. Mater. Sci. Eng. A 2012, 556, 164-169. [CrossRef]

17. Wu, Y.; Deng, B.; Ye, T.; Nie, Z.; Liu, X. Fabrication of Strong and Ductile AZ31 Magnesium Alloy Using High Strain Rate Multiple Forging in a Wide Temperature Range. Metals 2020, 10, 729. [CrossRef]

18. Tang, B.; Xiang, L.; Yan, Z.; Kou, H.; Li, J. Effect of strain distribution on the evolution of $\alpha$ phase and texture for dual-phase titanium alloy during multi-pass forging process. Mater. Chem. Phys. 2019, 228, 318-324. [CrossRef]

19. Konkova, T.; Rahimi, S.; Mironov, S.; Baker, N. Effect of strain level on the evolution of microstructure in a recently developed AD730 nickel based superalloy during hot forging. Mater. Charact. 2018, 139, 437-445. [CrossRef]

20. Park, N.K.; Kim, I.S.; Na, Y.S.; Yeom, J.T. Hot forging of a nickel-phase superalloy. J. Mater. Process. Technol. 2001, 111, 98-102. [CrossRef]

21. Zhu, S.; Yan, H.; Liao, X.; Moody, S.; Sha, G.; Wu, Y.; Ringer, S.P. Mechanisms for enhanced plasticity in magnesium alloys. Acta Mater. 2015, 82, 344-355. [CrossRef]

22. Li, Y.; Wu, S.; Bian, H.; Tang, N.; Liu, B.; Koizumi, Y.; Chiba, A. Grain refinement due to complex twin formation in rapid hot forging of magnesium alloy. Scr. Mater. 2013, 68, 171-174. [CrossRef]

23. Wu, Y.-Z.; Yan, H.-G.; Chen, J.; Zhu, S.-Q.; Su, B.; Zeng, P.-L. Hot deformation behavior and microstructure evolution of ZK21 magnesium alloy. Mater. Sci. Eng. A 2010, 527, 3670-3675. [CrossRef]

24. Wu, Y.-Z.; Yan, H.-G.; Zhu, S.-Q.; Chen, J.; Liu, A.-M.; Liu, X.-L. Flow behavior and microstructure of ZK60 magnesium alloy compressed at high strain rate. Trans. Nonferr. Met. Soc. China 2014, 24, 930-939. [CrossRef]

25. Wang, K.; Tao, N.; Liu, G.; Lu, J.; Lu, K. Plastic strain-induced grain refinement at the nanometer scale in copper. Acta Mater. 2006, 54, 5281-5291. [CrossRef]

26. Xiao, G.; Tao, N.; Lu, K. Effects of strain, strain rate and temperature on deformation twinning in a Cu-Zn alloy. Scr. Mater. 2008, 59, 975-978. [CrossRef]

27. Meyers, M.A.; Vöhringer, O.; Lubarda, V. The onset of twinning in metals: A constitutive description. Acta Mater. 2001, 49, 4025-4039. [CrossRef]

28. Yan, F.; Liu, G.; Tao, N.; Lu, K. Strength and ductility of 316L austenitic stainless steel strengthened by nano-scale twin bundles. Acta Mater. 2012, 60, 1059-1071. [CrossRef]

29. Zhu, S.-Q.; Yan, H.; Chen, J.; Wu, Y.; Liu, J.; Tian, J. Effect of twinning and dynamic recrystallization on the high strain rate rolling process. Scr. Mater. 2010, 63, 985-988. [CrossRef]

30. Pei, R.S.; Korte-Kerzel, S.; Al-Samman, T. Normal and abnormal grain growth in magnesium: Experimental observations and simulations, J. Mater. Sci. Technol. 2020, 50, 257-270. [CrossRef]

31. Bhattacharyya, J.; Agnew, S.; Muralidharan, G. Texture enhancement during grain growth of magnesium alloy AZ31B. Acta Mater. 2015, 86, 80-94. [CrossRef]

32. Wu, W.; Jin, L.; Zhang, Z.; Ding, W.; Dong, J. Grain growth and texture evolution during annealing in an indirect-extruded Mg-1Gd alloy. J. Alloy. Compd. 2014, 585, 111-119. [CrossRef]

33. Wu, Y.Z.; Yan, H.G.; Liu, X.L.; Li, L.; Li, X.; Yuan, D.L. Investigation of the high strain rate forging of ZK60 magnesium, J. Harbin Eng. Univ. 2017, 38, 478-483.

34. Sagapuram, D.; Efe, M.; Moscoso, W.; Chandrasekar, S.; Trumble, K.P. Controlling texture in magnesium alloy sheet by shear-based deformation processing. Acta Mater. 2013, 61, 6843-6856. [CrossRef]

35. Pérez-Prado, M.T.; Del Valle, J.; Contreras, J.; Ruano, O.A. Microstructural evolution during large strain hot rolling of an AM60 Mg alloy. Scr. Mater. 2004, 50, 661-665. [CrossRef]

36. Ono, N.; Nowak, R.; Miura, S. Effect of deformation temperature on Hall-Petch relationship registered for polycrystalline magnesium. Mater. Lett. 2004, 58, 39-43. [CrossRef]

37. Nan, X.-L.; Wang, H.-Y.; Zhang, L.; Li, J.-B.; Jiang, Q.-C. Calculation of Schmid factors in magnesium: Analysis of deformation behaviors. Scr. Mater. 2012, 67, 443-446. [CrossRef]

(C) 2020 by the authors. Licensee MDPI, Basel, Switzerland. This article is an open access article distributed under the terms and conditions of the Creative Commons Attribution (CC BY) license (http://creativecommons.org/licenses/by/4.0/). 